COSTA, E.M.S. et al. Carnitina na nutrição de aves e suínos. PUBVET, Londrina, V. 6, N. 31, Ed. 218, Art. 1451, 2012.

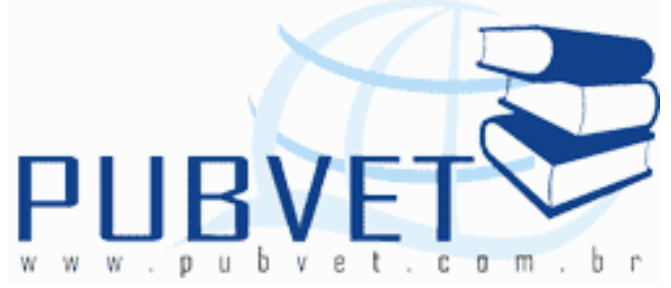

PUBVET, Publicações em Medicina Veterinária e Zootecnia.

\title{
Carnitina na nutrição de aves e suínos
}

\section{Elvania Maria da Silva Costa ${ }^{1}$, Agustinho Valente de Figueirêdo ${ }^{2}$, Snaylla Natyelle de Oliveira Almendra ${ }^{1}$, Hidaliana Paumerik de Aguiar ${ }^{1}$}

\begin{abstract}
${ }^{1}$ Mestranda do Programa de Pós-Graduação em Ciência Animal da Universidade Federal do Piauí. E-mail: ellvania@hotmail.com

${ }^{2}$ Professor do Departamento de Zootecnia da Universidade Federal do Piauí.
\end{abstract}

\section{Resumo}

Nos últimos anos, tem chamado a atenção de nutricionistas para uma interessante substância, a carnitina, desde então, tornar-se firmemente estabelecida na medicina humana e também se desenvolve em um complemento valioso na criação de animais. Animais superiores, incluindo mamíferos, podem sintetizá-la, no entanto, estudos recentes indicaram que a sua biossíntese pode ser limitada ou inadequada em certos animais. Sua administração pode melhorar o desempenho de monogástricos devido ao aumento da eficiência da utilização da energia dos lipídios, possibilitando a economia da proteína além de permitir a incorporação desta proteína na produção de tecido muscular. Com o objetivo de demonstrar a importância da carnitina na nutrição de aves e suínos esta revisão de literatura reúne várias informações, que mostram como esse nutriente é promissor no desempenho e na manutenção da saúde dos animais em destaque.

Palavras-chave: energia, L-carnitina, monogástricos. 
COSTA, E.M.S. et al. Carnitina na nutrição de aves e suínos. PUBVET, Londrina, V. 6, N. 31, Ed. 218, Art. 1451, 2012.

\title{
Carnitine in the nutrition de poultry and swine
}

\begin{abstract}
In recent years, has attracted the attention of nutritionists for an interesting substance, carnitine has since become firmly established in human medicine and also develops into a valuable supplement in animal husbandry. Higher animals, including mammals, can synthesize it. Recent studies have indicated that its biosynthesis may be limited or inadequate in some animals. Their administration can improve the performance of monogastric animals because of the increased efficiency of energy utilization of lipids, allowing the economy of the protein and allows the incorporation of this protein in the production of muscle tissue. In order to demonstrate the importance of carnitine in the nutrition of poultry and pork this literature review brings together various information, which shows that this nutrient is promising on performance and maintenance of animal health in focus.
\end{abstract}

Keywords: energy, L-carnitine, monogastric.

\section{INTRODUÇÃO}

Nos últimos anos, tem chamado a atenção de nutricionistas para uma interessante substância, a carnitina, desde então, tornar-se firmemente estabelecida na medicina humana e também se desenvolve em um complemento valioso na criação de animais.

Animais superiores, incluindo mamíferos, podem sintetizá-la. Estudos recentes indicaram que a sua biossíntese pode ser limitada ou inadequada em certos animais. O fígado e rins de mamíferos são capazes de sintetizá-la a partir de lisina e metionina, no entanto, a biossíntese endógena sozinha não é suficiente para manter suas concentrações em níveis adequados (DURAN et al., 1990). Assim, a indústria tem disponibilizado no mercado um composto natural: L-carnitina com a intenção de otimizar a utilização de nutrientes em algumas vias metabólicas, influenciando positivamente o desempenho dos animais. No entanto, a resposta ao seu uso varia de acordo com o animal. 
COSTA, E.M.S. et al. Carnitina na nutrição de aves e suínos. PUBVET, Londrina, V. 6, N. 31, Ed. 218, Art. 1451, 2012.

Como o organismo é altamente complexo e, a fim de alcançar perfeita atividade do eixo hipotálamo-hipófise-gonadal, uma interação ideal na base molecular é necessária, onde a L-carnitina pode ter sua ação direta.

A carnitina é responsável pelo transporte de ácidos graxos de cadeia longa através da membrana das mitocôndrias, onde serão oxidadas para geração de energia. Sua administração pode melhorar o desempenho de monogástricos devido ao aumento da eficiência da utilização da energia dos lipídios, possibilitando a economia da proteína além de permitir a incorporação desta proteína na produção de tecido muscular.

Essa substância tem sido estudada para verificar o efeito no crescimento, inferindo-se a possibilidade de aumentar a porcentagem de carne e diminuir a gordura na carcaça dos animais. As pesquisas com esse agente têm sido bastante intensas e devem continuar para elucidar os mecanismos de atuação.

Com o objetivo de demonstrar a importância da carnitina na nutrição de aves e suínos esta revisão de literatura reúne várias informações, que mostram como esse nutriente é promissor no desempenho e na manutenção da saúde dos animais em destaque.

\section{ASPECTOS GERAIS DA CARNITINA}

Foi descoberta em 1905 por dois cientistas russos Gulewitsch e Krimberg, tendo sido denominada de Carnitina por derivar do Latim caro, carnis (carne), eles observaram que esta substância era essencial para o funcionamento das células musculares. Em 1932 foi estabelecida sua estrutura química e desde seu isolamento do alimento tem sido estudada para o melhor conhecimento da importância fisiológica, porém suas funções metabólicas só foram consideradas a partir de 1955, quando pesquisadores observaram sua principal importância no metabolismo energético das células.

Devido à sua estrutura assimétrica no carbono dois, a molécula possui atividade óptica e existe em duas formas enantioméricas: a L-Carnitina e a DCarnitina. As iniciais "D" e "L" referem-se às orientações dadas às moléculas químicas. A molécula "D" (ou dextro molécula) possui rotação para a direita, 
COSTA, E.M.S. et al. Carnitina na nutrição de aves e suínos. PUBVET, Londrina, V. 6, N. 31, Ed. 218, Art. 1451, 2012.

mudando a rotação, mudam as propriedades químicas. A D-Carnitina não é recomendada para o consumo, não está presente nos alimentos e é biologicamente inativa, além de dificultar as atividades da L-carnitina, não ocorre na natureza, mas podem ser obtidos por síntese química, diferente da L-Carnitina que tem propriedades nutricionais (MARDONES et al., 1999).

Quimicamente, é definida como uma amina quaternária (3-hidroxi-4-Ntrimetil-aminobutirato) que caracteriza-se pela alta estabilidade térmica, com um ponto de fusão de mais de $210^{\circ} \mathrm{C}$, é um aminoácido derivado com o nome $\beta$-hidroxi-y-trimetil-aminobutyrate, com um peso molecular de 161 (Figura 1).

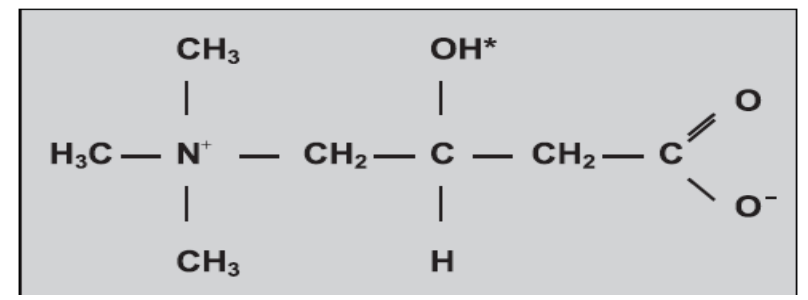

Figura 1. Estrutura química da Carnitina.

É hoje considerada por alguns autores como um aminoácido, por ser sintetizada no fígado e nos rins através de dois aminoácidos essenciais: lisina e metionina, estes servem como principais substratos para sua biossíntese são também necessários vitamina B6, vitamina B3, vitamina C e ferro como cofatores. Durante a síntese, L-lisina fornece a cadeia de carbono e o átomo de nitrogênio da carnitina e L-metionina fornece os grupos metila. A conversão de trimetilisina à carnitina requer duas hidroxilações catalisadas por duas monooxigenases específicas que usa cetoglutarato como um doador de elétrons para ativar o dioxigênio. Os a-aminoácidos são desmarcados em $\mathrm{CO}_{2}$ e succinato. As duas enzimas exigem Fe (II) e são ativadas por ascorbato.

L-carnitina ocorre naturalmente em microorganismos, plantas e animais (BREMER, 1983). É obtida através de biossíntese in vivo e fontes dietéticas, podendo ser suplementadas via oral em água potável. Na sua forma quimicamente pura, L-carnitina ocorre como um pó branco que é altamente solúvel em água. 
COSTA, E.M.S. et al. Carnitina na nutrição de aves e suínos. PUBVET, Londrina, V. 6, N. 31, Ed. 218, Art. 1451, 2012.

A carnitina é um constituinte normal do plasma, sua concentração nos animais varia muito de acordo com a espécie, tipo de tecido e estado nutricional do animal (RABIE et al., 1997). Em animais, ela é sintetizada quase que exclusivamente no fígado. Normalmente atende aos requisitos metabólicos em animais adultos, no entanto, deficiência de carnitina pode ocorrer em recém-nascidos ou em algumas situações, particularmente em doenças, assim, uma oferta de carnitina dietética é essencial (FAMULARO; DE SIMONE, 1995).

As principais fontes alimentares de L-carnitina são encontradas em carne, peixe, aves e produtos lácteos. Em geral, quanto mais vermelha a carne, maior o seu conteúdo em carnitina. Produtos lácteos contêm L-carnitina principalmente na fração de soro de leite. Verifica-se que produtos de origem animal apresentam concentrações de L- carnitina maiores do que aqueles de origem vegetal. No entanto, pouco L-carnitina é encontrado em grãos de cereais e seus subprodutos.

Tem sido sugerido que a exigência de L-carnitina pode ser aumentada em certas circunstâncias, como em várias condições de estresse e onde a dieta é deficiente em fontes de proteína animal.

\section{EFEITOS FUNCIONAIS DA L-CARNITINA}

A carnitina desempenha função fundamental na geração de energia pelas células de seres humanos e animais, age nas reações transferidoras de ácidos graxos livres de cadeia longa transferindo grupos acila do citosol para a matriz mitocondrial, local onde ocorre a beta oxidação destes ácidos graxos, facilitando sua oxidação e geração de adenosina trifosfato (TWIBELL; BROWN, 2000). A molécula de cadeia longa Acil-CoA, liga-se a carnitina para compor a Acil-carnitina, sendo que a deficiência de carnitina pode prejudicar a betaoxidação dos ácidos graxos de cadeia longa. O transporte é catalisado pela carnitina aciltransferase (CAT) e translocase acilcartina-carnitina (CT), a carnitina remove o excesso de grupos acila que podem desestabilizar a membrana mitocondrial (Figura 2). 
COSTA, E.M.S. et al. Carnitina na nutrição de aves e suínos. PUBVET, Londrina, V. 6, N. 31, Ed. 218, Art. 1451, 2012.

A suplementação de L-carnitina na dieta promove a $\beta$-oxidação dos ácidos graxos para gerar adenosina trifosfato (ATP), melhora a utilização de energia e, portanto, ganho de peso e eficiência alimentar, especialmente em animais jovens, onde a síntese é insuficiente para atender às necessidades endógenas (NEUMAN; LIN; HESTER, 2002).

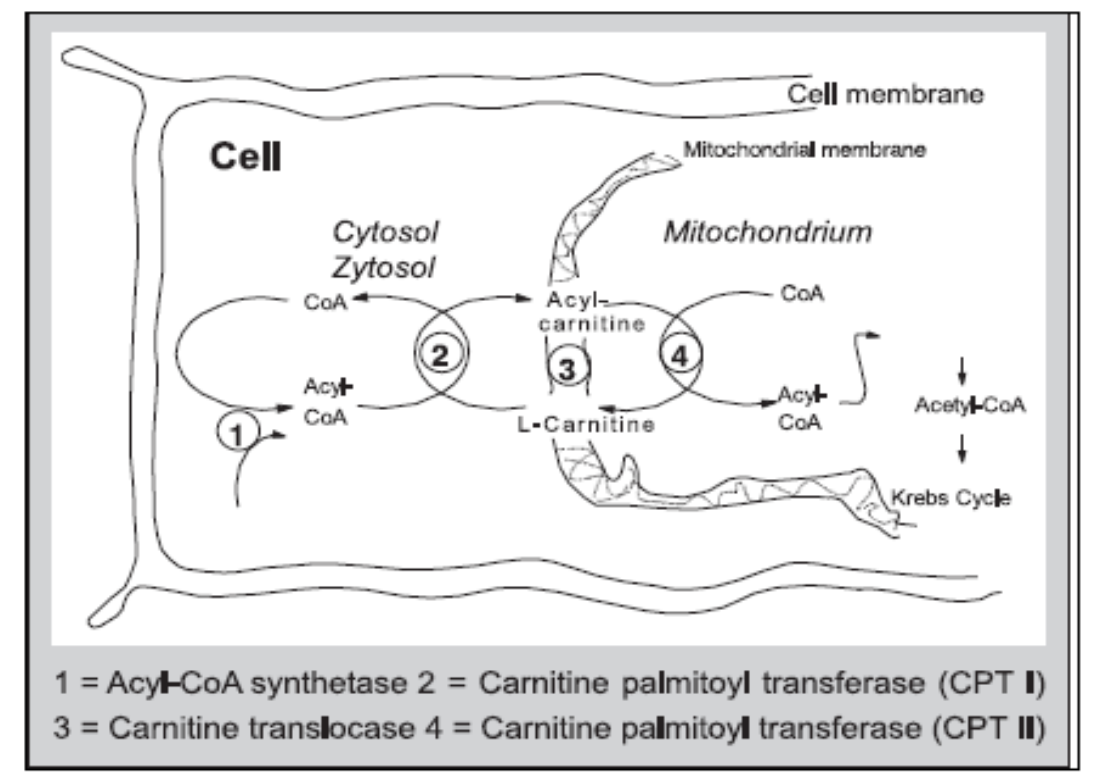

Figura 2. Sistema transportador de L-carnitina para a mitocôndria.

Além disso, por ser uma substância produzida no organismo em condições normais e com boa tolerabilidade, a suplementação de L-carnitina tem sido estudada em função de possíveis efeitos antioxidantes, seqüestrando radicais livres e protegendo as células do estresse peroxidativo. Antioxidantes tais como o ácido ascórbico e vitamina E, bem como enzimas antioxidantes, são protegidos contra possíveis peroxidação de L-carnitina.

Uma vez que a oxidação lipídica é um grande problema nos produtos enriquecidos com ácidos graxos poliinsaturados (PUFAs), pode ser uma das principais causas de deterioração de qualidade em carnes e produtos cárneos. Isso pode resultar na produção de odores, perda de pigmentos, de vitaminas solúveis em gordura e por gotejamento resultando em uma inaceitabilidade do 
COSTA, E.M.S. et al. Carnitina na nutrição de aves e suínos. PUBVET, Londrina, V. 6, N. 31, Ed. 218, Art. 1451, 2012.

consumidor (O'SULLIVAN et al., 2004). No entanto, estudos anteriores indicam que a oxidação lipídica em produtos enriquecido em PUFAs podem ser prevenidas por antioxidantes da dieta, como por exemplo, a L-carnitina que tem esse efeito.

A L-carnitina funciona através da redução da disponibilidade de lipídios para a peroxidação transportando ácidos graxos na mitocôndria para a $\beta$-oxidação para gerar energia ATP, isto reduz a quantidade de lipídios disponíveis para a peroxidação (RANY; PANNEERSELVAM, 2002).

L-carnitina também é capaz de reduzir as concentrações de colesterol circulantes, triglicerídeos, ácidos graxos livres, fosfolipídios e as lipoproteínas de muito baixa densidade (VLDL) e a aumentar as concentrações de lipoproteínas de alta, intermediária e baixa densidade (HDL, IDL, LDL, respectivamente).

É envolvida, direta ou indiretamente, em numerosos outros processos bioquímicos no organismo, incluindo a síntese e proteção de membranas celulares, reduzindo a capacidade de retenção de água, aumentando a energia consumida em potenciais eletroquímicos. Promove ativamente 0 desenvolvimento e a preservação do sistema imunológico (formação de anticorpos e atividade fagocitárias) e protege as células nervosas contra os efeitos tóxicos da amônia (FELIPO et al., 1994). Além disso, é essencial para espermatogênese e mobilidade do esperma. Certos problemas de fertilidade correlacionam diretamente com níveis de L-carnitina nos epidídimos e espermatozóides. Em particular, a mobilidade do esperma é diretamente dependente da quantidade de Acetilcarnitina armazenada nas células do esperma, servindo como fonte de energia primária para a mobilidade do esperma após a inseminação. 
COSTA, E.M.S. et al. Carnitina na nutrição de aves e suínos. PUBVET, Londrina, V. 6, N. 31, Ed. 218, Art. 1451, 2012.

\section{IMPORTÂNCIA DA L-CARNITINA}

\section{Nutrição de Aves}

A primeira evidência convincente para a biossíntese de carnitina em animais foi obtida em embriões de pinto, que continha uma quantidade significativa, porém nenhuma foi encontrada em ovos (BREMER, 1983).

$\mathrm{Na}$ produção de aves, L-carnitina tem finalidade multifuncional, que inclui: estimular o crescimento, fortalecer o sistema imunológico, efeitos antioxidantes e melhorar a qualidade do sêmen.

Nas duas últimas décadas há mais de 70 artigos publicados que tratam especificamente da aplicação de L-carnitine na produção avícola, porém os relatos são contraditórios. Por exemplo, 17 estudos não encontraram nenhum efeito de L-carnitina sobre o desempenho das aves, embora quase 14 estudos observaram que a taxa de crescimento vem melhorado com sua suplementação. É oportuno que estes relatórios conflitantes sejam agrupados e revistos.

$\mathrm{XU}$ et al. (2003) avaliaram o efeito da L-carnitina sobre o desempenho de frangos de corte machos, porém não obtiveram resultados significativos a medida que foram aumentados os níveis de L-carnitina dietética nos níveis de $0,25,50,75$ e $100 \mathrm{mg} / \mathrm{kg}$.

BARKER; SELL (1994) também não encontraram efeito da L-carnitina sobre o ganho de peso e consumo da ração em frangos de corte quando alimentado com 50 ou $100 \mathrm{mg} / \mathrm{kg}$, contrariamente a estes resultados, RABIE et al. (1997) relataram que a suplementação de Lcarnitina na dieta em três níveis $(50,100$ ou $150 \mathrm{mg} / \mathrm{kg}$ ) aumentou significativamente $o$ ganho de peso corporal de frangos de corte em comparação com aqueles em uma dieta basal. Assim, devem ser feitas futuras avaliações de L-carnitina no crescimento dos frangos, provavelmente deve- se usar uma maior concentração de carnitina dietética, especialmente por causa da limitada capacidade de absorção intestinal e sua considerável degradação no intestino. 
COSTA, E.M.S. et al. Carnitina na nutrição de aves e suínos. PUBVET, Londrina, V. 6, N. 31, Ed. 218, Art. 1451, 2012.

Apesar de suplementação dietética geralmente não melhorar o desempenho da ave (consumo de ração, crescimento), L-carnitina promove a redistribuição de lipídios no organismo, principalmente em frangos, aumentando a gordura intramuscular e diminuindo gordura subcutânea, depósitos de gordura abdominais e concentrações de triglicerídeos.

Apenas informações limitadas podem ser encontradas na literatura sobre - efeito da suplementação de L-carnitina na dieta sobre o rendimento de carcaça de aves.

Experimentos desenvolvidos por SARICA et al. (2007) foram realizados para determinar os efeitos de dietas contendo dois níveis de energia metabolizável $(12,13$ ou $11,72 \mathrm{MJ} \mathrm{ME} / \mathrm{kg}$ ) e duas diferentes fontes de gordura (de girassol e óleo de peixe) com ou sem suplementação de L-carnitina (0 ou $50 \mathrm{mg} / \mathrm{kg}$ da dieta) sobre características de carcaça da carne de codornas. O rendimento de carcaça fria com dietas contendo óleo de girassol foi significativamente maior do que aquelas dietas contendo óleo de peixe. Após 35 dias de alimentação, a dieta contendo o nível de energia padrão (12.13 ME $\mathrm{MJ} \bigvee \mathrm{kg}$ ) sobre o rendimento de coxa das aves foi significativamente maior do que dietas de energia mais baixa. Entretanto, observaram que a suplementação de L-carnitina nas dietas, não afetou o peso corporal no momento do abate, os pesos absolutos de carcaça eviscerada, o rendimento da carcaça quente, do peito, coxa e sobrecoxa, gordura abdominal e peso total das partes comestíveis incluindo fígado, coração e moela.

BARKER; SELL (1994) relataram que a suplementação dietética de Lcarnitina (50 ou $100 \mathrm{mg} / \mathrm{kg}$ ) não influenciaram o peso de gordura abdominal e rendimento de carne de peito de frangos de corte alimentados com dietas de baixo ou alto teor de gordura.

LEIBETSEDER (1995) investigou o efeito da L-carnitina e seus precursores (metionina e lisina) na redução da formação de gordura abdominal em frangos de corte alimentados com dietas suplementadas com 0 ou $50 \mathrm{~g}$ de gordura/kg, eles ressaltaram que o conteúdo de gordura abdominal de frangos 
COSTA, E.M.S. et al. Carnitina na nutrição de aves e suínos. PUBVET, Londrina, V. 6, N. 31, Ed. 218, Art. 1451, 2012.

de corte não foi influenciada pela suplementação de L-carnitina dietética em um nível de $200 \mathrm{mg} / \mathrm{kg}$ dieta.

LIEN; HORNG (2001) demonstraram que a suplementação de L-carnitina não influenciou significativamente a gordura abdominal e peso do fígado de frangos de corte.

RABIE; SZILAGYI (1998) relataram que o nível de energia da dieta, Lcarnitina ou a interação entre eles não afetaram o peso da moela, coração e vísceras de forma significativa. No entanto, eles encontraram um aumento significativo no rendimento da carne de peito e coxa e reduções significativas nos teores de gordura abdominal de frangos de corte. Eles também apontaram que uma redução no nível de energia da dieta de 13,5 para 12,2 MJ ME/kg em crescimento e terminação de frangos de corte, resultou em reduções significativas, diminuindo o peso corporal e concomitante os pesos de carcaça eviscerada, fígado e rendimento de carne de peito, coxa, o total de partes comestíveis e gordura abdominal de frangos de corte.

Estas inconsistências entre os estudos podem ser 0 resultado de diferenças nos níveis de suplementação de L-carnitina, nos níveis de metionina e lisina das dietas, as fontes de gordura utilizadas, os níveis de energia metabolizável bem como efeito dos sexos, estado fisiológico e idade das aves.

\section{Nutrição de Suínos}

O ganho de peso é um dos fatores de grande importância para a produção de monogástricos e talvez seja o de maior interesse quanto à suplementação da dieta com L-carnitina. OWEN et al. (1996) observaram uma melhoria no ganho médio diário de suínos alimentados com 250 ou $500 \mathrm{mg} / \mathrm{kg}$ de L-carnitina na dieta.

O maior crescimento que a suplementação de L-carnitina pode promover é atribuído ao aumento na utilização da energia, em consequência do aumento da queima de gorduras. Diferenças na composição da dieta, especialmente na 
COSTA, E.M.S. et al. Carnitina na nutrição de aves e suínos. PUBVET, Londrina, V. 6, N. 31, Ed. 218, Art. 1451, 2012.

quantidade de produtos lácteos (alta em carnitina) e idade de suínos pode ser um fator que responde à adição de L-carnitina dietética.

Estudos recentes têm mostrado que porcas alimentadas com dietas com L-carnitina durante a gestação e lactação melhoram seu desempenho reprodutivo. Em particular, as porcas alimentadas com dietas suplementadas com L-carnitina tinham ninhadas mais pesadas do que as porcas do grupo controle (RAMANAU et al., 2002). Os mecanismos bioquímicos subjacentes a estes efeitos de L-carnitina em porcas, não são totalmente compreendido. Devido à sua função, parece plausível que os efeitos de L-carnitina em porcas podem ser devido à maior $\beta$-oxidação de ácidos graxos. A suplementação da ração com L-carnitina aumentou em até $11 \%$ o consumo de ração pela fêmea em lactação, com reflexos positivos na produção de leite e no ganho de peso da leitegada (RAMANAU et al., 2004).

A L-carnitina também tem demonstrado afetar várias enzimas chave no metabolismo de lipídios e proteínas. Devido a estes efeitos, é possível que a Lcarnitina possa aumentar a produtividade reprodutiva de matrizes na gestação e na lactação. Foi observado que a suplementação de $250 \mathrm{mg} /$ dia de Lcarnitina na dieta de matrizes em lactação levou a uma redução na mortalidade pré desmame e no aumento de peso dos leitões ao desmame.

MUSSER et al. (1999) avaliaram o efeito da suplementação de Lcarnitina na dieta de gestação e de lactação sobre o desempenho reprodutivo de matrizes. Foi utilizada uma suplementação de $100 \mathrm{mg} /$ dia de L-carnitina, do $5^{\circ}$ ao $112^{\circ}$ dia de gestação, e de 50 ppm, durante a lactação. A suplementação com L-carnitina proporcionou um maior ganho de peso e uma maior espessura de toucinho na altura da última costela nas matrizes durante a gestação. As matrizes suplementadas com L-carnitina produziram leitões e leitegadas mais pesados ao nascer. Não houve efeito da suplementação de L-carnitina sobre a uniformidade do peso das leitegadas.

Por outro lado, a gestação é uma fase onde as necessidades de mantença são muito maiores do que durante o crescimento. Preenchidas as necessidades de mantença, os nutrientes são usados para o crescimento fetal 
COSTA, E.M.S. et al. Carnitina na nutrição de aves e suínos. PUBVET, Londrina, V. 6, N. 31, Ed. 218, Art. 1451, 2012.

e para a recuperação de reservas corporais de proteína e gordura perdidas na última lactação. Portanto, a partição de nutrientes é diferente nas fases de crescimento ou gestação. A L-carnitina aumenta a $\beta$ - oxidação em matrizes gestantes, em leitões recém-nascidos ou em terminação e isto pode determinar um aumento na oxidação dos triglicerídios da dieta. Entretanto, como as dietas de gestação são consideravelmente mais pobres em gordura do que as dietas de terminação, outros fatores podem influenciar a deposição de gordura (MUSSER et al., 1999).

Uma vez que o tecido muscular é fortemente dependente da gordura para energia, o músculo esquelético contém $90 \%$ do total de carnitina no corpo. Em suínos fetais, BALTZELL et al. (1987) relataram que músculo esquelético e cardíaco tinham altas concentrações de carnitina do que nos tecidos do fígado, intestino ou rins e que os níveis no músculo continuaram a aumentar durante a gestação, enquanto os níveis de carnitina nos outros tecidos diminuíram. O metabolismo lipídico é afetado principalmente quando há sintomas de deficiênicas de carnitina, resultando em acúmulo de gorduras nos músculos e anormalidades funcionais nos músculos cardíaco e esquelético. Essas desordens são manifestadas pelas baixas concentrações de carnitina no plasma, músculo, e fígado.

Embora a biossíntese de carnitina no fígado e nos rins aparece suficiente para as necessidades metabólicas de mamíferos adultos, L-carnitina dietética é necessária para manter a concentração normal de carnitina no recém-nascido. $\mathrm{Na}$ verdade, a capacidade de oxidação de ácidos graxos em suínos neonatos depende do fornecimento de L-carnitine.

KERNER et al. (1984) relataram que, a L-carnitina apesar de apresentar baixas concentrações hepáticas e no sangue de leitões recém-nascidos, altas concentrações de carnitina são encontradas no leite e colostro. Grandes quantidades de carnitina no leite e colostro são provavelmente responsáveis por quantidades maiores de carnitina no sangue e fígado de leitões com dois dias de idade, em comparação com os valores encontrados em leitões recémnascidos. 
COSTA, E.M.S. et al. Carnitina na nutrição de aves e suínos. PUBVET, Londrina, V. 6, N. 31, Ed. 218, Art. 1451, 2012.

A L-carnitina tem sido usada em concentrações de 50 a 1000 ppm em dietas de leitões ao desmame, encontrando melhoria nas taxas de ganho de peso, eficiência alimentar e redução de lipídios na carcaça. Essas diferenças tem por base melhorias na digestibilidade dos nutrientes. Esse efeito não é muito claro em animais de terminação, mas foi proposto por BONOMI (1995), que a suplementação de 300 ppm de L-carnitina para suínos abatidos com 160 $\mathrm{kg}$, permite aumentos de ganho de peso (10,5\%), eficiência alimentar $(12,8 \%)$, rendimento de carcaça $(7,2 \%)$ e aumento geral dos músculos e maciez da carcaça, devendo-se isso ao efeito favorável da carnitina no metabolismo lipídico. Existe uma hipótese de que suplementar a dieta de suínos com carnitina pode mudar a proporção entre proteína e secreção de gordura, produzindo um animal mais magro para o abate.

Resultados mais recentes de OWEN et al. (2001) não relataram qualquer efeito da L-carnitina no desempenho de suínos lactentes, e efeitos mínimos na secreção diária de lipídios. Todavia, o autor cita que em suínos em crescimento e em terminação há redução da gordura dorsal e aumento da carcaça magra. A sua suplementação na dieta diminui a deposição de gordura em suínos em crescimento e terminação.

Vários estudos em uma variedade de espécies têm relatado melhor equilíbrio de azoto $(\mathrm{N})$, redução de gordura corporal e/ou aumento de acreção de proteínas após a suplementação de L-carnitina (RABIE; SZILAGYI, 1998). No entanto, estudos que avaliam o efeito da carnitina sobre suínos em crescimento têm rendido resultados inconsistentes.

\section{CONSIDERAÇÕES FINAIS}

Atualmente a criação de animais, com demandas para alto desempenho na reprodução e crescimento, o corpo do animal necessita de uma oferta adequada de L-carnitina. Em muitos casos, é incapaz de atender a síntese endógena, os requisitos e a suplementação na dieta de animais monogástricos, é efetiva na maioria das pesquisas publicadas, parece ser uma estratégia útil, 
COSTA, E.M.S. et al. Carnitina na nutrição de aves e suínos. PUBVET, Londrina, V. 6, N. 31, Ed. 218, Art. 1451, 2012.

pois ajuda a superar os gargalos de energia com o mínimo de perdas no desempenho animal.

\section{REFERÊNCIAS BIBLIOGRÁFICAS}

BALTZELL, J. K. et al. The neonatal piglets as a model for human neonatal carnitine metabolism. Journal Nutrition. p.754. 1987.

BARKER, D. L.; SELL, J. L. Dietary carnitine did not influence performance and carcass composition of broiler chickens and young turkey fed low- or high- fat diets. Journal Poultry Science. p. 281-28. 1994.

BREMER, J. Carnitine-metabolism, functions. Physiological Reviews. p.1420-1480. 1983.

BONOMI, A. Revista de Suinocultura. p. 49-55. 1995.

DURAN, M. et al. Secondary carnitine deficiency. Journal of Clinical Chemistry \& Clinical Biochemistry. p.359. 1990.

FAMULARO, G.; DE SIMONE, C. A new era for carnitine?. Immunology today. p. 211-213. 1995.

FELIPO V, K. Molecular mechanism of acute ammonia toxicity and of its prevention by Lcarnitine. Advances in Experimental Medicine Biology. p. 65-77. 1994.

KERNER, J. et al. A study of acylcarnitine content of sows' colostrum, milk and newborn piglet tissues: Demonstration of high amounts of isovaleryl-carnitine in colostrum and milk. Journal Nutrition. p. 854-861. 1984.

LEIBETSEDER, J. Studies on effects of L-carnitine in poultry. Archives of Animal Nutrition. p. 97-108. 1995.

LIEN, T. F.; HORNG, Y. M. The effect of supplementary dietary L-carnitine on the growth performance, serum components, carcass traits and enzyme activities in relation to fatty acid betaoxidation of broiler chickens. British Poultry Science. p. 92-95. 2001.

MARDONES, $C$. et al. Enantiomeric separation of D- and L-carnitine by integrating on-line derivatization with capillary zone electrophoresis. Journal of Chromatography. p. 609-616. 1999.

MUSSER, R.E. et al. Effects of L-carnitine fed during gestation and lactation on sow and litter performance. Journal of Animal Science. p. 3289-3295. 1999.

NEUMAN, S. L.; LIN, T. L.; HESTER, P. Y. The effect of dietary carnitine on semen traits of White Leghorn roosters. Journal Poultry Science. p. 495-503. 2002.

OWEN, K. Q. et al. Effect of Lcarnitine and soy-bean oil on growth performance and body composition of early-weaned pigs. Journal of Animal Science. p. 1612-161. 1996.

OWEN K. Q. et al. Dietary L-carnitine suppresses mitochondrial branched-chain keto acid dehydrogenase activity and enhances protein accretion and carcass characteristics of swine.

Journal Animal Science. p. 3104-3112. 2001. 
O'SULLIVAN, C. M. et al. Use of antioxidants in chicken nuggets manufactured with and without the use of salt and/or sodium tripolyphoshate: effects on product quality and shelflife stability. Journal Poultry Science. p. 345-353. 2004.

RABIE, M. H. et al. Influence of dietary L-carnitine on performance and carcass quality of broiler chickens. Acta Biologica Hungarica. p. 241-252. 1997.

RABIE, M. H.; SZILAGYI, M. Effects of Lcarnitine supplementation of diets differing in energy levels on performance, abdominal fat content and yield and composition of edible meat of broilers. British Journal of Nutrition. p. 391-400. 1998.

RANI, P. J. A.; PANNEERSELVAM, C. Effect of L-carnitine on brain lipid peroxidation and antioxidant enzymes in old rats. Journal of Gerontology Series A: Biology Science and Medical Sciences. p. 134-137. 2002.

RAMANAU, A. et al. Reproductive performance of sows supplemented with dietary L-carnitine over three reproductive cycles. Archives Animal Nutrition. p. 287 -296. 2002.

RAMANAU, A. et al. Supplementation of sows with L-carnitine during pregnancy and lactation improves growth of the piglets during the suckling period through increased milk production.

Journal Nutrition. p. $86-92.2004$.

SARICA, S. et al. Effects of dietary supplementation of L-carnitine on performance, carcass and meat characteristics of quails. South African Journal of Animal Science. p. 189-200. 2007.

TWIBELL, R.G.; BROWN, P.B. Effects of dietary carnitine on growth rates and body composition of hybrid striped bass Morone saxatilis male x M. chrysops female. Aquaculture, v.187, p.153-161, 2000.

$\mathrm{XU}, \mathrm{Z}$. R. et al. Effects of L- carnitine in growth performance, carcass composition, and metabolism of lipids in male broilers. Journal Poultry Science. p. 408-413. 2003. 